\title{
La co-presencia de ritual, símbolo y logos en la cultura griega antigua: Del Daimon-Mana al Dios olímpico y de éste al Logos del Ser
}

\author{
Josetxo BERIAIN \\ Universidad Pública de Navarra \\ josetxo@unavarra.es \\ Javier GIL-GIMENO \\ Universidad Pública de Navarra \\ fcojavier.gil@unavarra.es
}

Recibido: 21-10-2015

Aceptado: 16-02-2016

\section{Resumen}

Frecuentemente pensamos la cultura de una sociedad como un conjunto de patrones de significado gestionados por la razón, por el Logos. Este trabajo se cuestiona dicho planteamiento y apuesta por la confluencia dinámica de aspectos mimético-rituales, de aspectos simbólico-míticos y de aspectos racionales. Utiliza como estudio de caso la transición de la religión griega antigua, representada por el mito-ritual del Enyautos-Daimon, que se refleja en una sacralización simbólica que parte de la naturaleza, y se desliza hacia la religión olímpica, representada por una sacralización de lo divino expresada en Zeus, Dios central del panteón griego, del que surgirá el principio ontológico metafísico del Logos del Ser.

Palabras clave: Daimon; Mana, Kouretes; tragedia, Juegos Olímpicos; Religión; Grecia; ritual; Dios.

\section{The Co-presence of Ritual, Symbol and Logos in Ancient Greek Culture: \\ From Daimon-mana to Olympian God and to the Logos of Being}

\begin{abstract}
Normally we think about the culture of a society as a pattern of meanings guided and shaped by Reason, by the Logos. This coauthored paper questions that approach, and puts in place the dynamic confluence of mimetic-ritual domains, symbolic-mythic domains and rational domains, using the shift of the old greek religion as a case study, represented by the myth-ritual of the Enyautos-Daimon, which is a reflection of a symbolic sacralization that starts in the nature and slides to the olympic religion, which represents a sacralization of the divine, expressed by Zeus, central God of the greek pantheon, from which shall arise the metaphysical-ontological constellation of meaning of the Logos of Being.

Key words: Daimon; Mana; Kouretes; tragedy; Olympic Games; religion; Greece; ritual; God.
\end{abstract}

\section{Referencia normalizada}

Beriain, J. y J. Gil-Gimeno (2016): "La co-presencia de ritual, símbolo y logos en la cultura griega antigua: Del Daimon-Mana al Dios olímpico y de éste al Logos del Ser”, Política y Sociedad, 53 (3), pp. 733-755.

Sumario: Introducción. 1. La génesis social de las formas culturales según Merlin Donald y Robert N. Bellah. 2. La génesis social del Daimon-mana en el Enyautos-Daimon griego. 3. La teogonía, el Dios 
olímpico y la diferenciación entre la naturaleza y el ser humano. 4. La metafísica del Logos como secularización del Dios olímpico. 5. Conclusiones. 6. Bibliografía.

Le sacré, cést le pére de Dieu.

Le Dieu, cést le sacré personifié (fait personne humaine).

Jane Ellen Harrison

\section{Introducción}

Este trabajo se centra, en primer lugar, en el análisis de la génesis social del ritual del Himno de los Kouretes, del origen de los Juegos Olímpicos y de la Tragedia, así como de las representaciones colectivas que les sirven de base en la formación originaria de la cosmogonía griega y de su sistema simbólico pre-axial en torno al concepto de Daimon-Mana. En segundo lugar, aborda la transición desde tales representaciones colectivas politeístas hacia una conciencia colectiva apoyada en Zeus como Dios olímpico y centro del panteón. Finalmente, abordamos la irrupción de la metafísica del Logos, categoría que representa la razón, el fundamento, el ser.

Parece que este elemento racional, el Logos, podría ser capaz de gobernar y guiar el resto de nuestra persona, salvándonos así de vivir a merced de la fortuna, del accidente, de la coincidencia, de la contingencia (Láchesis). Pero si estamos tentados de pensarlo, debemos ser conscientes de que la Razón ocupa el lugar de Zeus como éste había ocupado previamente el de la Moira. Así, a diferencia de una concepción teleológicafinalista según la cual el último estadio hace tabula rasa de los anteriores, condenándolos a la 'egiptianización', nuestra propuesta subraya la co-presencia de los tres momentos en una suerte de diferenciación de funciones que, como veremos, son indispensables para la sociedad. Para realizar esta labor nos apoyaremos en las investigaciones clásicas de Émile Durkheim, en Les Formes Elementaires de la vie religieuse (1912), así como en el extraordinario trabajo de Jane Ellen Harrison: Themis. A Study of the Origins of the Greek Religion, publicado en el mismo año que Las Formas, y deudor de las tesis de aquél, tal y como lo señala la propia autora en numerosas ocasiones a lo largo de su obra.

\section{La génesis social de las formas culturales según Merlin Donald y Robert N. Bellah}

El enfoque metodológico que nos va a permitir adquirir una visión englobante de los tres momentos mencionados -la emergencia de la cosmogonía, la teogonía y tecnogonía y la metafísica del Logos- lo tomamos de investigaciones realizadas por Merlin Donald 
(1991) y por Robert N. Bellah $(2011,2012)$. Según estos estudios, en el análisis de la génesis social de los estadios de evolución de la cultura y de la cognición, podemos distinguir un primer estadio en la cultura mimética desarrollada por el Homo erectus, es decir, por los primates y los australopitecos, hace unos 2.000.000 de años. En él, se pone de manifiesto un aumento del tamaño del cerebro y la emergencia del más básico de los niveles de representación: la habilidad imitativa para reeditar eventos.

La mímesis es un modo gestual de expresión inherentemente reduplicativo y colectivo en su naturaleza, convierte la arena pública de la acción en teatro. En este sentido, la forma primordial distintivamente humana de cultura está orientada performativamente. Los humanos son actores e, inicialmente en su forma arcaica, el rostro público de esa cultura mimética ha sido un teatro de acción personificada, manifiesta en la emergencia de patrones ritualizados de cultura práctica. Ejemplos de ello pueden ser las migraciones estacionales coordinadas, los campamentos compartidos y alguna división rudimentaria del trabajo. El Homo erectus tuvo la habilidad de ensayar y evaluar, y así afinar sus propias acciones. El entrenamiento es esencialmente una acción mimética donde el individuo debe repetir una actividad performativa previa con la finalidad de practicarla y mejorarla. Este tipo de imaginación mimética sobrevivirá en la naturaleza esencialmente teatral de las relaciones humanas (Goffman, 1967; Collins, 2009), así como en la música y en las artes visuales.

La transición del Homo erectus al Homo Sapiens, que se produce hace 250.000100.000 años marca un nuevo estadio evolutivo, el representado por la cultura mítica, caracterizada tanto por el surgimiento del sistema del habla como nueva modelización del universo de la existencia humana, así como por el surgimiento de la metáfora y la narrativa. Este tránsito de una forma puramente mimética de cultura al lenguaje hablado, a la narrativa, y a una cultura oral-mítica completamente desarrollada supone un progreso revolucionario que precipita un tránsito en la representación propia de las costumbres miméticas de movimientos lentos hacia la capacidad narrativa grupal. Esta adaptación introduce un nuevo estrato de cultura con la consecuencia de que tanto la cognición humana como las formas culturales asociadas a ella se hacen más complejas y diversificadas. La expresión pública de esta nueva habilidad narrativa se manifiesta en una imaginación liberada que faculta a los seres humanos a reorganizar eventos más complejos en la imaginación o incluso a inventar eventos ficticios -como ocurre en la narrativa y en la fantasía- permitiendo de esta guisa la emergencia de variaciones sin límite en cuanto a cómo pudiera ser construida la realidad del grupo.

Hace aproximadamente 40.000 años, surge un tercer estadio: la cultura teórica. En ella, el 'hardware' que contribuye al despliegue de esta nueva adaptación no es ya biológico sino tecnológico, y está apoyado en la invención gráfica, en la construcción teórica y en el despliegue de una 'memoria externa'. El cerebro humano ha coevolucionado junto a sus culturas cognitivas a lo largo de más de dos millones de años y ha alcanzado un punto donde no puede realizar su diseño potencial fuera de la cultura. La estructura de la mente se ha fijado cada vez menos en el neo-cortex. Así, a medida que progresa la evolución, actuamos dentro de 'colectividades cognitivas' en simbiosis con sistemas externos de memoria como las religiones del Libro, los museos, las bibliotecas, los templos, los monumentos, etc. Esta tercera transformación ha 
conducido a una de las más grandes re-configuraciones de la estructura cognitiva, y todo ello sin haberse producido grandes cambios genéticos en la historia de los mamíferos. De hecho, nuestros genes son prácticamente idénticos a los de un chimpancé o un gorila, pero nuestra arquitectura cognitiva es mucho más compleja. Por tanto, dicha tercera transformación está indisociablemente unida a esas 'colectividades cognitivas' de las que hablamos. Nos hemos hecho más complejos, multi-dependientes, mentes híbridas que portan en su interior -como individuos y como sociedades- toda la herencia evolutiva de los dos pasados millones de años.

Habitualmente pensamos que la fase mimética de nuestro desarrollo como seres humanos es superada por la fase simbólica, donde construimos imágenes y representaciones simbólicas de la realidad, y que esta fase es, a su vez, superada en la fase conceptual-teórica donde el pensamiento abstracto hace tabula rasa de todo lo anterior. Pero no sucede esto ya que un nuevo estadio supone más bien una reconfiguración de viejas y nuevas posibilidades, en lugar de una superación y desaparición de los estadios anteriores. Lo interesante del modelo de Donald y Bellah, frente a todo historicismo o teleologismo ilustrado, es que nos permite entender las fases evolutivas sin un sesgo finalista en donde la cultura teórica habría erradicado los desarrollos mimético y mítico.

\section{La génesis social del Daimon-mana en el Enyautos-Daimon griego}

\subsection{El acontecimiento apropiador del ritual. Ejemplos}

\subsubsection{El Himno de los Kouretes}

Habitualmente pensamos en el mundo griego clásico como uno de los orígenes de la civilización occidental, situando las filosofías de Sócrates y Platón como 'representaciones canónicas' de la cultura teórica, del Logos, en donde la resolución consciente en orden a des-encantar el mundo no trata solo del propio mundo, sino que también es un esfuerzo para guiar los propios pensamientos. Se trataría de pensar sobre el propio pensamiento (Elkana, 1986:40-65; Meier, 1986:65-92). Pero este estadio de pensamiento presupone, como veremos a lo largo de este trabajo en los términos de Harrison, un "lower (presocratic) stratum of thought" (1912, vii) sin referencia al cual es imposible entender aquél. Nuestro planteamiento inicial va a consistir en desvelar la génesis social de las prácticas rituales que permiten determinar tal estrato de pensamiento.

Según nuestro punto de partida, la génesis social de la proto-distinción directriz que diferencia entre las categorías epistemológico-analíticas de 'lo sagrado' y 'lo profano', solo resulta viable a partir de las prácticas rituales que reproducen al colectivo social como tal. Para Durkheim, a diferencia de Max Weber que consideraba las religiones como sistemas de creencias, esta proto-clasificación no tiene su origen en creencias porque, si así fuera, no tendría un origen empírico en el ritual. De hecho, la razón para la realización performativa de tales prácticas es mantener el límite entre 'lo sagrado' y 'lo profano', y no tanto una creencia en seres sobrenaturales o en dioses misteriosos, como pretenden las concepciones convencionales de la religión. 'Lo sagrado' no existe como una idea o creencia previa, sino que solo a través del ritual viene a la existencia. 
La existencia de 'lo sagrado' precede a la esencia-creencia en lo sagrado: "Solo a través del acontecimiento apropiador del ritual emerge lo sagrado (y sus figuras: daimones, dioses, hombres) como algo diferenciado de lo profano" (Beriain, 2015:4-7). En este sentido, 'lo sagrado' representa esa instancia que sirve para dibujar tanto la visión del mundo del grupo en cuestión como su propia identidad.

En nuestro estudio de caso concreto, el de la religión griega antigua, dicha instancia es representada por el Himno de los Kouretes (Harrison, 1912:1-29), que nos va a ofrecer ese primitivo rito de iniciación tribal (Enyautos-Daimon) (Harrison, 1912:16), que expresa performativamente la cosmovisión originaria griega del mundo. Descubrimientos arqueológicos son los que permiten a Jane E. Harrison rescatar la sintaxis del ritual, así como ahondar en su sentido interpretativo profundo. El Himno consta de tres fases (Harrison, 1912:9 y ss.): Una primera de invocación en la que Zeus es interpelado como un joven inmortal, como un Kouros. Una segunda de performatividad ritual, donde los participantes (Kouretes), armados con escudos y en medio de una efervescencia emocional, separan al joven de su madre, lo ocultan, lo 'matan', lo desmembran y esparcen sus restos en la naturaleza ${ }^{1}$. Finalmente en la tercera fase, el joven reaparece, se le trae nuevamente a la vida, resucita y es el portador del bienestar colectivo.

Como vemos, en el Himno, los Kouretes, hombres jóvenes iniciados, invocan al Daimon, el Gran Kouros, parte humana y parte divina, o como señala Harrison "la materia de la que están hechos los dioses" (Harrison, 1912:25), que funge claramente como la proyección simbólica de una comunión ritual (Thiasos) de sus fieles. Es el centro de una danza mágica, así como el vehículo de un culto sacramental primitivo. El Gran Kouros expresa la encarnación simbólica del cuerpo de los Kouretes y, coextensivamente, del cuerpo social. El coro de fieles (Thiasos), o más bien los agentes sociales, son anteriores a las diferentes figuras de lo sagrado -ya sean estos daimones y/o dioses-. En este sentido, el acto ritual es anterior a la divinidad, es lo que le sirve de sostén. El joven, el Gran Kouros, el Daimon, re-nace en el ritual ya no de su madre Sémele (en el caso de Dyonisos) o Rea (en el caso de Zeus), sino de la sociedad que lo invoca por medio de una emoción socializada, sentida colectivamente.

Pero, ¿cómo se consigue un estado de comunión (Schmalenbach, 1977:64-126) grupal característico? Durkheim sitúa a la práctica ritual como ese 'acontecimiento apropiador' que produce un tipo de realidad diferente, una 'efervescencia colectiva' (Durkheim, 1982), un 'éxtasis colectivo', una 'energía emocional', es decir, es esa condición de posibilidad a través de la cual el grupo experimenta una realidad diferente y más profunda. El sociólogo francés describe los rituales de los aborígenes australianos donde todo tipo de procesiones, danzas y canciones tienen lugar a la luz de las antorchas y donde la efervescencia general se incrementa al comenzar la caída de la noche: "Una vez alcanzado tal estado de exaltación, el hombre pierde la conciencia de sí mismo. Sintiéndose dominado, arrastrado por una especie de fuerza exterior que le

${ }^{1}$ Conviene observar el paralelismo del desmembramiento y posterior esparcimiento en la naturaleza del Himno de los Kouretes con la figura de Dionysos-Zagreo en Las Bacantes de Eurípides, cuya narrativa mitológica es la misma. 
hace pensar y actuar de modo distinto a como lo hace normalmente, tiene naturalmente la impresión de haber dejado de ser él mismo. Le parece que se ha convertido en un nuevo ser: las galas con que viste, las especies de máscaras con las que se cubre la cara, son representaciones materiales de esta transformación [...] Y como, al mismo tiempo, todos sus compañeros se sienten transfigurados de la misma manera y exteriorizan su sentimiento en sus gritos, gestos y actitudes, todo se desarrolla como si realmente fuera transportado a un mundo especial, completamente diferente de aquél en que vive de ordinario, a un espacio poblado por completo de fuerzas excepcionalmente intensas, que le invaden y metamorfosean" (Durkheim, 1982: 312-13/205). Las palabras de Durkheim revelan, pues, que los sentimientos colectivos y el pensamiento colectivo caminan juntos. Por lo tanto, el punto sociológicamente relevante no es qué estructura social subyace a ese estrato de pensamiento, sino el principio general de que la estructura social (sus rituales constitutivos) y la conciencia colectiva que la expresa, subyacen a toda constelación de lo sagrado.

Está claro que el acto de comunión ritual unifica al colectivo, pero ¿en torno a qué? La acción, la energía emocional y los sentimientos compartidos no pueden prolongarse durante mucho tiempo activados por el simple hecho de constituir una intensificación de la existencia colectiva. Es aquí donde interviene la propia sociedad a través de un proceso de sublimación simbólica en la que se objetiva el símbolo. Éste, como muy bien lo ha advertido George H. Mead, es la marca de la transición del puro estímulo biológico a la re-presentación simbólica (1982: 101-107). Representa un logro evolutivo de consecuencias enormes, puesto que transforma la acción mimética en acción simbólica, "prolongándose de esta guisa la vida de los sentimientos intensificados ritualmente" (Collins, 2009: 58-59). De hecho, "los sentimientos sociales carentes de símbolos, solo podrían tener una existencia precaria. Muy fuertes mientras los hombres están reunidos y se influyen recíprocamente, estos sentimientos no subsisten cuando la asamblea ha terminado, más que en forma de recuerdos que, si se los abandona a sí mismos, van empalideciendo progresivamente; pues, como el grupo en tales momentos ya no es algo presente y actuante, los temperamentos individuales entran necesariamente en una pendiente de bajada [...] De este modo, el emblematismo (del símbolo-tótem), necesario para que la sociedad pueda tomar conciencia de sí misma, no es menos indispensable para asegurar la continuidad de tal conciencia" (Durkheim, 1982: 330-31/216-17).

El símbolo-tótem recoge el sentir colectivo y se proyecta como referente de la identidad del grupo. De esta guisa, el Himno de los Kouretes funge de representación mítico-simbólica de un rito de muerte mimética y de resurrección (simbólica) practicado en una ceremonia de iniciación. Además, el Himno funge de 'rito de paso', de ceremonia de transición entre el salir de lo viejo y entrar en lo nuevo, en la que el Gran Kouros ejerce de Medicine-Man que desvela ese 'bautismo social' (Harrison, 1912: 19) del joven, ese 'To Be Born Again', ese 'volver a nacer (a la vida social)' o 'Segundo Nacimiento', esa resurrección social como miembro de la sociedad, más allá de su (primer) nacimiento biológico. De hecho, hasta que el muchacho no ha nacido otra vez, no puede asistir a los ritos de entierro de su propio padre. Sin ese re-nacer no es parte todavía del clan (Harrison, 1912: 21, Nota 1), de la sociedad. 
Así, el ritual es la expresión de una emoción, una cosa sentida, en la acción, mientras que el mito es algo apalabrado y ulteriormente pensado. El mito-ritual expresado en el Himno primaveral de los Kouretes pone de manifiesto que la expresividad performativa que lleva consigo el ritual da origen a un tipo de realidad sagrada: el Daimon (Mana, Orenda, Wakonda, son fuerzas mágicas similares presentes en colectivos primitivos en el mismo estadio de desarrollo en Australia, las Islas del Pacífico sur, el noroeste canadiense, Sudamérica). Se trata de esa "potencialidad mágica" (Mauss, 1978: 122133) que proyecta el carácter dinámico y renovador de la naturaleza en la propia sociedad. Es ésta una 'trascendencia inmanente' todavía sin una referencia divina, abstracta, individualizada, separada de 'este mundo'. En este estadio evolutivo la figura que expresa lo sagrado no es la divinidad, sino un Daimon, una fuerza imaginal, una 'potencialidad mágica', como la que Weber sitúa en el trasfondo de los nuevos ascetas seculares de la modernidad tardía (Weber, 1975: 230-231).

Podríamos decir que, en este estadio de evolución sociocultural, el grupo es intelectualmente débil pero emocionalmente fuerte. El acto ritual es algo $r e$-hecho o prehecho (Harrison, 1912: 43), algo re-presentado. Cuando suceden los acontecimientos apropiadores de la vida colectiva -cuyos protagonistas son héroes de gestas militares, deportivas, profetas, etc.-, la comunidad los inserta en el seno de la memoria colectiva o en una narrativa mítica, a través de las re-actualizaciones rituales. En esas actividades performativas constitutivas, el elemento de acción es re-hecho, imitado. Cuando los hombres regresan de la guerra, de la caza, de un viaje, y re-presentan sus acciones, escenifican acciones que ya han tenido lugar. Su drama es historia o al menos narrativa, pues ellos proclaman algo que, en efecto, ya ha sucedido. La batalla particular, la caza específica o el viaje concreto, son olvidados o suplantados por una sucesión de actos similares en un lapso de tiempo. En este sentido, el ritual viene a rememorar (re-cordar) y, a la vez, a con-memorar (recordar en comunidad, conjunta o colectivamente) la batalla, el viaje o la caza. El acto singular sucede primero, pero tiene un recorrido limitado, sin embargo, el plural de su re-presentación nos saca del acto singular concreto y le da un carácter generalizado.

\subsubsection{El origen de los Juegos Olímpicos}

La tarea que nos proponemos en el presente epígrafe es explicar el carácter religioso que subyace en los orígenes de los juegos olímpicos clásicos, aquéllos que se celebraron entre los años 776 y 393 a.C. Para centrar la tarea acudimos a Francis M. Cornford (1912) que, en un capítulo compilado en la obra de Harrison, nos ofrece un magnífico recorrido por los orígenes de los juegos olímpicos de la Grecia Clásica. De una lectura detenida del texto del filólogo británico se desprenden dos ideas fundamentales para comprender el origen religioso de éstos: en primer lugar, su vinculación con la celebración de una festividad en honor a Zeus y, en segundo lugar, el papel testimonial que la competición deportiva desempeñaba en dicha celebración. Desarrollamos estas dos ideas conjuntamente.

Según señala Cornford, el origen de los juegos olímpicos no está asociado con la celebración de la festividad en su totalidad o con su significado extenso, sino con una parte de la misma: la de la elección del Kouros anual, esto es, del mejor de los jóvenes 
(significado de Kouros). Si atendemos a lo que señala la mitología, los Kouretes fueron los encargados de cuidar, custodiar y proteger a Zeus niño cuando su padre, Cronos, le buscaba para matarle (situación que, como veremos, se repetirá en el caso del origen de la tragedia, pero en este caso con Dionysos como protagonista). El motivo por el que Cronos quería darle muerte es porque la diosa Gea había predicho que sería derrocado por uno de sus hijos, tal y como él había hecho previamente con su padre. Ante el temor de que Zeus fuera 'devorado' por su progenitor, su madre Rea le esconde en la isla de Creta y ordena su custodia y protección a los Kouretes, quienes cumplen con su misión y permiten la supervivencia del futuro 'rey de los dioses'.

En el contexto de la festividad ritual dedicada a Zeus, se celebraba una carrera para elegir a dicho 'mejor entre los jóvenes', a quien posteriormente le rendirían honores con la interpretación del himno analizado en el epígrafe anterior, que venía acompañado por una danza ritual. Es aquí donde encontramos el origen de los juegos olímpicos.

Los privilegios asociados a dicha victoria en la carrera de elección del kouros se pueden agrupar, fundamentalmente, en dos: en primer lugar, serlo durante un año o periodo ${ }^{2}$, lo que nos permite establecer un claro vínculo de continuidad entre dicha celebración y las festividades relacionadas con el renacimiento del Enyautos-Daimon o espíritu anual, tal y como señalábamos en el epígrafe anterior. El kouros ganador re-nace como un ser adulto que puede participar en la sociedad y que, debido a su gran victoria, desempeña un papel relevante en la misma. El segundo privilegio está asociado con dicho papel o función asignada al kouros anual, ya que sería el encargado de encabezar la procesión que conduciría a la comunidad y al animal sacrificial -un toro- al recinto sagrado de la divinidad, en donde se desarrollaría la parte central del rito. Así, señala Cornford: "hemos comenzado este capítulo con la declaración de que la procesión triunfal o komos, era el meollo original de los Juegos Olímpicos, algo que podría parecer, en el sentido estricto de la palabra, absurdo. Pero a la vista de los hechos que hemos analizado y de la discusión previa del Ditirambo, no nos parecerá paradójico sugerir ahora que esta procesión, con su sacrificio y con la ingesta de un toro, su himno al héroe y la conclusión del festín en la sala del banquete, era el rito central, del cual la carrera de los Kouretes era un mero ejercicio preliminar" (Cornford, 1912:256).

De lo comentado en la cita anterior se desprende que el tránsito que se produce hasta llegar a la realidad que glosa Píndaro, en sus Olímpicas (1967), en las que los vencedores comienzan a adquirir un pequeño protagonismo, digamos 'nominal', o la que observamos en la actualidad en la que los campeones olímpicos son venerados como héroes o como una especie de 'súper-hombres', es un evidente reflejo de algunas de las transformaciones que se han producido a escala macro-social, como pueden ser la paulatina pérdida de peso de las explicaciones y de las representaciones ultraterrenas sobre las acciones de los sujetos y de los colectivos sociales, el desarrollo de los procesos de individualización o el consecuente fenómeno de la 'sacralización de la persona' (Joas, 2014). Pero el 'héroe' al que se presenta en este estadio inicial no es

${ }^{2}$ Señalamos año o periodo, ya que no está claro que dicha festividad se celebrara anualmente. La idea es que el Kouros lo fuera durante un lapso de tiempo que, en la actualidad, no podemos determinar con total seguridad. 
un hombre muerto con un nombre conocido y una historia conmemorada por una serie de juegos funerarios. Su título no representa a una individualidad personal sino a una agencia institucional definida por sus funciones, en realidad es un 'funcionario' que ha conseguido su posición en un juego competitivo limpio. El desarrollo de la tragedia, a partir del siglo V a.C., mostrará el hiatus creciente existente entre los mortales y los dioses que la nueva concepción desmaterializada de los dioses ofrece y que, en Platón, vendrá representada por la idea de que el hombre mismo está dividido en parte divina (el alma) y en parte mortal, animal (el cuerpo).

Originariamente en los juegos olímpicos, que comienzan con una carrera a pie "por el reino" (Cornford, 1912: 255), el Kouros del Himno cretense que hemos analizado comparece como el Lider de sus Daimones. La carrera, cuyo propósito original fue determinar quién debería ser el Gran Kouros o Rey de ese año en concreto, se desarrolló con el tiempo en la forma de deportes atléticos, que tardíamente vienen a representar la característica fundamental de todo el festival. ¡Viva, el Rey Heracles (Hércules)!, es el Daimon encarnado en el ganador de la prueba que, en buena medida, representa al objeto de culto de la conmemoración. El ganador olímpico funge de Daimon de ese año, de héroe local y rey (Cornford, 1912: 256-257), de los juegos realizados normalmente en la primavera. Sin duda, la explicación de Cornford revela un proceso de sustitución de la parte por el todo, en la que un apartado del rito religioso original -la carrera para la elección del Kouros del año- muta en una ceremonia ritual laica convertida en fenómeno global de masas: las olimpiadas modernas. Como él mismo señala, "La carrera, cuyo propósito original era simplemente determinar quién debería ser el gran Kouros (el mejor de los jóvenes) o Rey del año, perfeccionado por sucesivas adiciones gracias a la elaboración de los deportes atléticos, que posteriormente se convertirían en el atractivo central del festival" (Cornford, 1912:256), pasa a constituirse en un acto competitivo olímpico, des-ritualizado.

\subsubsection{El origen ritual de la tragedia}

Una vez analizado el origen ritual-religioso de los juegos olímpicos, pasamos a hacer lo mismo con la tragedia. En su "Excursus on the ritual forms preserved in Greek Tragedy" (1912), Gilbert Murray establece una relación entre las danzas rituales sacer ludus- en honor al dios Dionysos (forma originaria del ditirambo), los dramas relativos al Enyautos-Daimon y los orígenes de esta forma literaria, convertida en arte por autores de la Grecia clásica como pueden ser Esquilo o Sófocles.

Etimológicamente hablando, la mayoría de aproximaciones a la raíz trag- (del griego trasgos) arrojan, principalmente, dos resultados: 'macho cabrío' y 'los placeres relacionados con la comida'. Esta primera idea ya nos permite establecer una aproximación etimológica entre Dionysos y la tragedia, ya que los animales sacrificados en las celebraciones en su honor solían ser o bien un chivo -o macho cabrío- o bien un toro. Es más, uno de los epítetos asociados a este dios es egóbolo, 'matador de cabras'.

Pero sigamos avanzando. Si aceptamos como válida la primera acepción de la raíz trag-, y la unimos con el sufijo -edia (del griego aeido), esto es, 'yo canto', tragedia significaría algo así 'canto en honor al macho cabrío'. Tal y como señala el filólogo Joan Coromines, en su Diccionario (2008: 549), esta es la definición con un 
mayor grado de aceptación académica. Con el sufijo -edia ha emergido otro de los ingredientes fundamentales para el desarrollo de este epígrafe: la idea de oda o canto, directamente relacionado con la danza y el ritual. Y es que, como han documentado sobradamente sociólogos y antropólogos (Durkheim, 1982; Cornford, 1912; Hubert y Mauss, 1964; Girard, 1995; o Turner, 1988, entre otros), durante los ritos sacrificiales -y más concretamente durante la matanza del propio animal en el altar sacrificial- se entonaban una serie de cantos y se realizaban una serie de danzas. Éstas cristalizarían, posteriormente, en lo que conocemos como ditirambo o, "en la antigua Grecia, composición poética en loor de Dionysos" (RAE, 2005: 489). Además, 'ditirambo' es uno de los epítetos con los que se conocía a Dionysos y viene a significar, como apunta Robert Graves (2002: 70), 'el hijo de la doble puerta' o el 'dos veces nacido'.

Sin duda, ésta es una clara alusión a su origen y a la persecución que sufrió por parte de su madrastra, Hera, antes de nacer. Zeus fue infiel a su esposa con la mortal Sémele, quedando ésta embarazada de Dionysos. Ésto desató los celos y la orghé de la diosa, que tramó una argucia para acabar con Sémele y, por lo tanto, también con Dionysos. Hera consiguió parcialmente su propósito ya que dio muerte a Sémele. Al verla muerta, Zeus decidió extraer el feto de Dionysos (primer nacimiento) y cosérselo en su muslo para que el proceso de gestación no se detuviese. Una vez dicho proceso hubo terminado, Dionysos nació de la pierna de su padre (re-nacimiento o segundo nacimiento). Como podemos observar, la historia se repite. Zeus salva a su hijo de la misma forma que él fue salvado por su madre -Rea - de las garras de su padre Cronos. Y si la historia se repite, la estructura del ritual que la rememora también. Volvemos a encontrarnos una ceremonia de celebración de re-nacimiento, pero en este caso, aunque la idea del kouros sigue presente en lo que respecta a su función de 're-novación' o 'renacimiento' en la vida social, pierde la asociada a la protección, ya que los encargados de custodiar a Dionysos no son los kouretes enviados a la isla de Creta, sino su propio padre, Zeus.

Así, como ocurría en el caso de los juegos olímpicos, volvemos a encontrarnos con elementos básicos de la práctica ritual de tipo religioso: danza ritual, oda o himno, mito de re-nacimiento y celebración performativa de recuerdo y conmemoración de lo que Giesen denomina "evento epifánico" (2006: 337).

Después de haber realizado este breve paréntesis mitológico, nuestra siguiente tarea es conectar el ditirambo con la tragedia. Realizando un somero análisis de estas composiciones, podemos observar que el nombre dado a los danzantes del ditirambo es trasgos, es decir, 'machos cabríos', tal y como señalábamos anteriormente. Del mismo modo, tampoco es baladí que la referencia más antigua que se conserva de un ditirambo sea el texto escrito en el siglo VII A.C. por Arión, titulado Himno al macho cabrío.

Las cuestiones comentadas en los párrafos anteriores son evidencias que nos hacen vislumbrar una solución de continuidad entre las danzas rituales en honor a Dionysos, la composición poética conocida como ditirambo y la tragedia. Pero va a ser Murray quien nos va a proporcionar la solidez necesaria para certificar dicha continuidad. En su texto de 1912, realiza un exhaustivo estudio de los orígenes y la evolución de la tragedia griega. En este contexto, lo primero que debemos destacar es la siguiente idea: 
"en el desarrollo histórico de la Tragedia se produce un proceso de diferenciación" (Murray, 1912: 344).

Para Murray, el elemento clave en el proceso de autonomización de la tragedia es su progresiva diferenciación con respecto al drama satírico y al ditirambo. Para explicarlo, alude a tres momentos o fases por las que atraviesa dicha relación. La primera se produce en el contexto de las representaciones rituales en honor a Dionysos y al Enyautos-Daimon en las que el drama satírico y la tragedia aparecen indiferenciados. En la segunda, con el paso del tiempo, los dramas representados con motivo de estas celebraciones comienzan a articularse estructuralmente del siguiente modo: "En tetralogías divididas en tres tragedias y un drama satírico [...]. El drama satírico estaba situado al final de la tetralogía, y representaba la llegada jubilosa del renacido Dionysos" (Murray, 1912: 343). Y, en la tercera y última, la tetralogía se rompe, provocando la separación definitiva entre la tragedia y el drama satírico.

Pero Murray no se conforma con explicar las tres fases que acabamos de analizar, sino que va un paso más allá proponiendo un estudio comparativo entre la estructura de los dramas del Enyautos-Daimon y la que presentan algunas de las tragedias clásicas más significativas. A este respecto, el filólogo británico señala que la estructura de estos dramas estaba constituida por cinco momentos o fases: 1. El Agon o prueba en la que "el Año se enfrentaba a su enemigo, la luz contra la oscuridad, el verano contra el invierno" (Murray, 1912: 342). 2. Un Pathos o sufrimiento del Daimon del año, generalmente una muerte ritual o sacrificial. 3. Un Mensajero que anuncia a la comunidad la muerte y que les dirige hacia 4. Un Threnos o lamentación. 5. Finalmente, se produce la teofanía o manifestación de la divinidad, que comprende dos elementos: la Anagnorisis y la Peripeteia. La primera es la revelación, descubrimiento o reconocimiento de una serie de datos del protagonista previamente desconocidos. En estos dramas dicha anagnorisis está asociada a la resurrección o renacimiento del Daimon tras su muerte ritual. En este sentido, la teofanía está totalmente asociada a la anagnorisis, y se completa con la peripeteia o cambio emocional extremo que hace que los participantes en la celebración comunitaria pasen from grief to joy, esto es, de la pena producida por el asesinato a la alegría generada por la resurrección del Daimon. Y es que, según Murray, en este momento se produce un "choque de emociones contrarias, la muerte del viejo ser unida al triunfo del nuevo" (Murray, 1912: 342).

En el tránsito hacia la tragedia, se suceden una serie de variaciones en la estructura analizada en el párrafo anterior que son las que, de acuerdo a Murray, le otorgan una entidad independiente con respecto a los ya analizados dramas de muerte y renacimiento del espíritu anual, a los dramas satíricos y al ditirambo. Dichas variaciones se pueden agrupar en torno a tres cuestiones: El papel desempeñado por la peripeteia, la situación que acontece tras la disolución de la unidad tragedia-drama satírico -introducida unos párrafos más arriba- y la aparición del 'pro-logos' como elemento diferencial. Detengámonos brevemente en cada una de ellas.

En primer lugar, hemos observado que la peripeteia que se produce en los dramas del Enyautos-Daimon siempre opera mediante una transición que dirige a la comunidad de fieles desde la pena al júbilo. Murray señala que, en términos de tragedia, se produce una inversión en dichos términos: "La peripeteia que ocurre en la tragedia, no transita 
habitualmente de la pena al júbilo sino, al contrario, del júbilo a la pena. Nuestras tragedias, normalmente, acaban con una reconfortante teofanía, pero no con una explosión de júbilo" (Murray, 1912: 343).

En segundo lugar, para Murray la inversión que se opera en términos de peripeteia puede ser explicada por la separación que se produce entre la tragedia y el drama satírico. La disolución de la tetralogía formada por tres tragedias y un drama satírico provoca, principalmente, una consecuencia: que la trilogía trágica se quede sin un final -recordemos que, en el caso de los dramas del Enyautos-Daimon, ese final se articulaba con el satyr play (drama satírico) y en este contexto es en el que, normalmente, se producía la transición de la pena al júbilo-. Ante dicha escisión, los autores de las tragedias se encontraban con dos posibilidades: “Debería terminar -la obra- con un threnos y confiar su epifanía (o su teofanía) al distinto e irrelevante drama satírico que se desarrollará más tarde?, ¿o debería ignorar el drama satírico y plantear una teofanía propia? Ambos tipos de tragedia se producen, pero la segunda tiende a predominar gradualmente" (Murray, 1912: 344).

Finalmente, Murray propone la aparición del pro-logos como una variación fundamental en el tránsito que se produce hacia la tragedia $\mathrm{y}$, por lo tanto, como un elemento diferencial de la misma con respecto a sus formas primitivas. Y es que el pro-logos permite dos acciones fundamentales para comprender el trasfondo de este sub-género literario: contextualiza, esto es, sitúa la escena y, además, permite el establecimiento de un diálogo con el coro, algo que multiplica las opciones de trama. Como comenta Murray "Cuando la naturaleza de la danza era algo obviamente dictado para la ocasión [...] no era necesaria ninguna explicación de fondo. Pero tan pronto como aparece algo como la tragedia, el caso torna diferente. La danza sagrada de Dionysos podía estar referida a Agamenón, o a Edipo, o a los hermanos de Danae, o a cualquier otro. Consecuentemente, era necesario un Pro-logos, o algo hablado antes. La palabra sugiere prosa antes que verso" (1912: -360).

Queremos concluir el presente epígrafe dedicando unas líneas a la idea de performatividad, ya que la encontramos tanto en los rituales y los dramas que se representaban con motivo de la celebración del ritual Enyautos-Daimon como en las tragedias -ya sean éstas clásicas o modernas-. Como nos recuerda Giesen "Las representaciones rituales no son eventos, sino iteraciones de eventos. Ellos repiten eventos que han tenido lugar previamente. Solo por esta referencia al pasado pueden llegar a ser visibles los rituales como representaciones estandarizadas. Esta estandarización y formalismo son el núcleo del proceso ritual" (2006: 338). A pesar de que ambas prácticas tienen una vocación claramente performativa, la tragedia -sobre todo en la actualidad- ya no nos remite a un horizonte de tipo religioso-supramundano en el que se lleva a cabo una celebración de ese 'evento epifánico fundador' y, por lo tanto, pretérito de un estado de cosas -tal y como ocurría con los dramas del Enyautos-Daimon-, sino a otro en el que la epifanía está relacionada con la propia experiencia emocional que proporciona la representación en sí misma -ya sea a actores o a espectadores- y por las interacciones que se producen entre actores y espectadores. Esto no significa que la tragedia haya eliminado el carácter de trascendencia característico de los dramas que se celebraban con motivo de la resurrección del espíritu anual sino que, de la misma forma 
que ocurre con los juegos olímpicos en la época actual, dicha trascendencia se adquiere de otros modos. "El poder de la representación teatral deriva de ser un evento para una audiencia: interrumpe la continuidad de la realidad profana, presenta algo inesperado y extraordinario, abre un espacio para lo que hemos denominado identidad colectiva de lo sagrado. A este respecto la realidad teatral tiene que diferenciarse estrictamente de la vida cotidiana mundana" (Giesen, 2006: 346).

Lo que comenta Giesen para la representación teatral en general lo podemos extrapolar a la tragedia en particular. Esa 'interrupción de la realidad profana' de la que habla, habilita el espacio para la aparición de una experiencia diferente, tremendum et fascinans (Otto, 2012), pero adaptada a una 'identidad colectiva de lo sagrado' concreta que no es similar a aquélla en la que tenían lugar las celebraciones relativas al EnyautosDaimon. Este no es sino un ejemplo más de la transformación o evolución religiosa que estamos analizando en el presente artículo.

\subsection{Totemismo, sacramento y sacrificio}

Junto al rito de iniciación de los kouretes en Creta mencionado anteriormente, donde se sacrificaba una cabra montesa o trasgos, se sitúa el ritual no menos importante de la Omophagia o Comida de la Carne Cruda en Tracia, en el que se sacrificaba un toro. Ambos son rituales de fertilidad que proyectan los ciclos de la naturaleza dentro de la sociedad. Es en este último donde se inscribe toda la narrativa mitológica del culto a Dionysos, cuya expresión literaria más acabada se encuentra en Las Bacantes de Eurípides. El conjunto de actividades cotidianas que forman parte de la vida del colectivo, como la caza, la pesca, el viaje, así como el compartir la comida del animal que se ha atrapado, están siempre re-presentadas en los rituales. Los ritos se dirigen a obtener la benevolencia de lo que se ha cazado -el toro, en nuestro caso-, así como a recibir el regalo de los poderes sagrados. Toda vida, toda subsistencia es ofrecida, y este regalo tiene que ser reorganizado. En este momento, todavía no existen los dioses como figuras, como materializaciones de lo sagrado. Los humanos no se ofrecen a los dioses como 'dobles imaginarios', si lo hicieran se privarían de su propia humanidad. Al contrario, "inventan daimones o dioses con el objeto de no perder su propia humanidad" (Hénaff, 2010: 167). Es esencial para ellos situar figuras de intercambio en el mundo a las que puedan responder por lo que han recibido. El bienestar está garantizado en el dar y recibir, en el intercambio, ese es el regalo de la vida, el "gift-giving" del que habla Mauss (1978: 155-269). Podemos decir que los daimones están ahí para encarnar esto que es dado, son sus figuras vivientes, integran toda la naturaleza y toda actividad de subsistencia en una alianza con los humanos. Es un mundo encantado más que un mundo divino. No existe una separación entre el mundo natural y el mundo social, sino una alianza de seres vivos que comparten un espacio y un tiempo comunes. Este estadio de pensamiento totémico no conoce dioses, solo una conciencia colectivamente sentida de Daimon-Mana común. El mundo natural es el mundo social.

William Robertson Smith agitó, en 1889, los descubrimientos sobre los estudios dedicados al totemismo y el ritual. Según él (1889: 320), la base del sacrificio primitivo no era tanto el don, el regalo, el dar y recibir, sino el hecho de comer juntos en medio de una comida de comunión tribal (Eranos). Ahora bien, a pesar del nuevo horizonte 
que presenta, Robertson-Smith no se pudo liberar de las concepciones tradicionales de la religión, el animismo y el antropomorfismo. Para él, el sacrificio representaba una comida comensal, pero compartida con el Dios. Este era el modo a través del que se renovaba la vida de ambos, comensales y Dios. Una vez consumido el animal sagrado su mana pasa a quien lo ha comido, al fiel, y el circuito se completa. Pero, a diferencia de Robertson-Smith, tenemos que decir que, en lo que respecta a nuestro análisis, no existe Dios misteriosamente presente en el banquete, transfiriendo la santidad al animal que se hace sagrado por el hecho de haber sido sacrificado. No existe tercer factor. El toro sacrificado en el ritual de la Omophagia o Comida de la Carne Cruda no representa un sacrificio a Zeus o a otro Dios olímpico sino una comida comunal. Cuando los participantes en el ritual han sacrificado al toro, lo reparten entre todos aquéllos que participan en el ritual. El toro no es un regalo a Zeus sino un vehículo del Daimon-Mana para ser distribuido entre la gente, el toro es algo sagrado pero no divino. El toro sagrado es fuente de mana. Él es comido porque es santo y es santo por la potencialidad mágica ('Daimon-Mana') que in-habita dentro de él. Éste tiene algo de forma cambiante, se metamorfosea. Así, Dionysos aparece como joven humano, pero también como león, como serpiente, como toro salvaje, como llama ardiendo. En este sentido, la religión primitiva se centraría en la representación común de las necesidades y las circunstancias que constituyen la vida colectiva, pudiendo considerarse plausiblemente a la comida (cruda), lo que es bueno para comer, como el bien supremo originariamente (Harrison, 1912: 139).

Pero poco a poco, a partir del sacrificio del toro, emergerá una figura divina de la fiesta, imaginada, encarnada antropomórficamente y proyectada de forma trascendente, Zeus, como divinidad central del panteón olímpico. ¿Qué factores influyen en esa transición de la alianza-intercambio entre seres vivos mediados por el Daimon-Mana al sacrificio como mediación entre humanos y dioses?

\section{La teogonía, el Dios olímpico y la diferenciación entre la naturaleza y el ser humano}

Para responder a la pregunta con la que concluíamos el epígrafe anterior podemos aducir dos razones fundamentales: La primera de ellas, el surgimiento del altar como lugar sacrificial (Harrison, 1912: 147), que desplaza a la comida comunal cimentada en la idea de 'todos iguales'. En el sacrificio en el altar se proyectan tres figuras distintas: el que ofrece, la víctima sacrificial que se ofrece y a quien se ofrece, y el Dios separado de los mortales. La segunda razón es que, paulatinamente, el valor religioso ya no reside en la identificación total con el grupo, en los términos de Durkheim, sino que empieza a adquirir la forma de una diferenciación entre el mundo trascendente y el mundo inmanente (Schwartz, 1975: 3-4).

Concretamente, ¿qué significa 'trascendencia' (Eisenstadt, 1982, 1985) en estas nuevas constelaciones religiosas? Este término implica que emerge una separación cuasi-espacial entre lo intra-mundano y lo divino en esas religiones y filosofías, y que nuevas ideas han sido desarrolladas a partir de la existencia de un ámbito supra-mundano, trascendente, de forma absoluta y no a partir de una 'trascendencia inmanente' como 
sucedía en la religión totémica estudiada por Durkheim y Harrison. En la época de la religiosidad pre-axial, lo sagrado estaba en el mundo y era parte del mundo, es decir, no existía una separación entre lo divino y lo mundano y, por tanto, los espíritus y los dioses podían ser directamente influenciados y manipulados por el hecho de ser parte del mundo, a través del intercambio y la alianza.

Con la emergencia de las nuevas religiones de redención y de las filosofías de la Era Axial, se crea un hiatus entre ambas esferas. La idea directriz radica en que lo divino es lo Otro actual, verdadero e irrefutable, y lo mundano, en comparación, solo puede ser inferior. Esta tensión entre lo mundano y lo trascendente tendrá importantes consecuencias. Por ejemplo, la noción de un gobernante divino (Wittrock, 2012: 118) -como sucedía en la religiosidad de Babilonia, en la religiosidad mesoamericana prehispánica o en las dinastías del antiguo Egipto- ya no es compatible con tal diferenciación. Éste no puede ser ya a imagen de Dios debido a que los dioses 'ocupan' otro ámbito, el ámbito de lo trascendente, o el de lo 'absolutamente Otro' en los términos de Otto (2012). Esto significa que incluso el gobernante podría ser obligado a justificarse a sí mismo ante los mandamientos divinos. Es en este contexto en el que aparece el conflicto sobre el Dios auténtico y la correcta interpretación de los mandamientos divinos precisamente por el surgimiento de una clase reflexiva de especialistas, intelectuales, sacerdotes, clérigos, filósofos, literati.

Volvamos a la transición del modelo de alianza al modelo del sacrificio. Marcel Hénaff (2010), apoyándose en una original reinterpretación de las teorías del don y del sacrificio de Mauss, apunta la interesante y documentada idea de que los colectivos de cazadores y recolectores utilizan la alianza, esto es el "gift-giving", el intercambio de la comida comunal, mientras que los colectivos agro-ganaderos se basan en el uso indiscriminado del sacrificio (Hénaff, 2010: 163-175). Hemos visto que el DaimonMana no es algo propiedad de los dioses, sino que circula entre el animal, la planta y los humanos, generando un intercambio simétrico y horizontal. Sin embargo, la creación del hiatus mencionado entre humanos y dioses generará otro tipo de intercambio asimétrico y vertical (Hénaff, 2010: 150). Entonces, ¿por qué la inmolación se hace necesaria?, ¿cómo puede ser entendida la destrucción sacrificial? Según Hénaff, el sacrificio sería el proceso a través del cual, inmolando a un ser vivo, los humanos restauran a los dioses el control último sobre la naturaleza y, co-extensivamente, sobre la vida, parte de la cual se habían apropiado los humanos3: "Haciendo esto, ellos aseguran que su propio poder permanece dentro del propio sistema de reciprocidad (entre el hombre y la naturaleza). Cuando se ha recibido mucho (de la naturaleza y, ulteriormente, de los dioses), mucho se debe devolver. El sacrificio restaura una relación de intercambio que parecía debilitarse o incluso amenazaba con desaparecer [...] Siempre, en el momento en que los humanos desarrollan sus capacidades técnicas y reducen su dependencia del mundo natural, simbólicamente limitan este poder adquirido a través de la práctica

\footnotetext{
${ }^{3}$ Según Anaximandro, el principio y elemento de todas las cosas es "lo indeterminado (apeiron) [...] Ahora bien, a partir de donde hay generación para las cosas, hacía allí se produce también la destrucción, según la necesidad; en efecto, pagan la culpa unas a otras y la reparación de la injusticia, según el ordenamiento del tiempo" (1981, Vol. 1: 129, F183).
} 
del sacrificio. Este límite hace referencia a aquello sobre lo que no puede decidir el hombre: el tiempo, el renacimiento de la vida, la fertilidad de las plantas y los animales, el tiempo de vida garantizado antes de la muerte, los eventos accidentales, y los deseos y voluntades de los otros" (Hénaff, 2010: 173).

Una nueva línea de separación emerge no solo entre humanos y dioses, sino también entre humanos y animales, entre el mundo cultivado y el mundo salvaje. Los 'daimones' habían permanecido como compañeros asociados del lado de la naturaleza, ahora los 'dioses' se convierten en poderes superiores del lado de la cultura. Este es un cambio sustancial. Los dioses se hacen invisibles e inaccesibles porque son eliminados del mundo circundante y son situados como 'divinidades trascendentes'. La necesidad del sacrificio como nuevo dispositivo social de mediación surge toda vez que los dioses se han distanciado de los humanos y han dejado de 'habitar' la naturaleza. Según Hénaff, la subsistencia debida a las deidades "ya no consistirá en animales o plantas presentes en la naturaleza sino en el cultivo humano de plantas, en la salud de animales domesticados, en la regularidad de las estaciones, y en la fertilidad de la tierra. Los dioses deben dar a los humanos lo que estos tomaron de ellos" (Hénaff, 2010:188).

Del mismo modo, la explicación sobre el origen del mundo también cambia, la cosmogonía se convierte, de alguna manera, en tecnogonía. Quien mejor representa esta idea es el mito de Prometeo. El arquetipo de Prometeo se manifiesta en las hechuras míticas configuradas por el "robo a Zeus del fuego, engendrador de todo arte, para darlo a los mortales" (Esquilo, 1981:74; Hesíodo, 1981:10-11), realizado por el semi-dios, por el Titán Prometeo. En el relato mítico, este robo, esta desobediencia a los dioses del Olimpo (con Zeus a la cabeza) es castigada. Prometeo es encadenado a una roca en el Cáucaso por haber revelado a los hombres los secretos divinos, y los dioses le envían un águila para devorar su hígado. Aguijoneado por el dolor de su pico desgarrador, Prometeo se va hundiendo en la roca hasta hacerse uno con ella. Con el medio de la auto-preservación, Prometeo ha dado al hombre la libertad en y con la que desarrollar más plenamente un mundo de formas que habían sido el producto de la mera necesidad. El fuego es un instrumento 'a la mano' para conquistar el mundo. Ya no será necesario celebrar el ritual de la Omophagia o de la Carne Cruda. A través del fuego, Prometeo introduce la importante diferenciación entre lo crudo y lo cocido-asado.

El sacrificio trae a nuestras mentes modernas un altar tan inevitable como trae consigo un Dios. Como hemos visto previamente, el Kouros surge a partir de la emoción colectiva de sus fieles, pero ahora podemos percibir otra fuente de la divinidad: el sacrificio. Sacrificar es santificar, literalmente, hacer sagrado, y hacer sagrado es entrar en contacto con Dios como la expresión novísima de lo sagrado. "El sacrificio es un acto religioso, que a través de la consagración de una víctima, modifica la condición moral de la persona que lo propicia" (Hubert y Mauss, 1964:13). El sacrificio sirve para "establecer un medio de comunicación entre lo sagrado y lo profano a través de la mediación de una víctima" (Hubert y Mauss, 1964: 97). A diferencia del planteamiento que propone Robertson-Smith, para Hubert y Mauss la víctima no viene necesariamente al sacrificio con una naturaleza religiosa ya perfeccionada y definida, sino que es en y a través del sacrificio como adquiere ésta. La víctima es sacrificada, sacralizada y entonces divinizada: "Dios, en este estadio, es lo sagrado personificado 
(hecho persona)" (Harrison, 1912: 148). El Daimon-Mana co-presente en todas las instancias, con distintas figuras, fitomórficas y teriomórficas, adquiere figura humana, se personifica. Veamos cómo se produce la génesis social de esta nueva forma de lo sagrado.

La tensión dinámica se proyectará a partir de ahora entre el nuevo orden y el viejo orden, entre los daimones-mana asociados a la Tierra, a la naturaleza, y los dioses (theoi) del Olimpo (con Zeus y Apolo como dioses centrales del Olimpo) y, coextensivamente, entre los daimones y theoi matriarcales que representan a la fuerza genesíaca de la tierra y el sistema patriarcal de los nuevos dioses. La transformación se realiza del Daimon-Mana de la naturaleza al Dios de naturaleza humana. Esto supondrá una serie de importantes cambios que pasamos a analizar:

a) Moira (Cornford, 1984: 57 y ss.) significa literalmente 'parte' o 'lote asignado' y de aquí se deriva el significado de 'destino'. Tanto los dioses como los hombres tienen Moirai. Cada Daimon posee su parte o dominio asignado, esto es, cierto espacio de la naturaleza o campo de actividad. La Moira pre-axial está también por encima de todos y cada uno de los dioses axiales olímpicos y los límites que impone a sus poderes son de naturaleza social y moral. Hesíodo destaca, mediante la secuencia temporal, la preponderancia de la Moira sobre las divinidades que nacerían después. El orden de la cosmogonía de Hesíodo implica que la división del mundo en dominios era más antigua que los dioses $\mathrm{y}$, a la vez, afirma que éstos tomaron forma en sus respectivos dominios y surgieron de esos mismos elementos. Así, la voluntad de los dioses comienza a hacer valer sus pretensiones frente a la inevitable asignación del destino. El poder impersonal de la Moira se personaliza en los diferentes dioses, así se comienza a hablar del 'hado de Zeus' o del 'destino de Dios'.

b) El Dios olímpico se desprende progresivamente de su forma de planta o de animal, personificándose. La imaginación preolímpica representaba a un Zeus con cabeza de toro sentado en el Olimpo, y así aparece en multitud de relieves a lo largo de Grecia. Pero, sobre todo y lo más importante, la forma animal pervive en la mitología a través de unicornios, minotauros, toros alados, etc.

c) El Dios olímpico rechaza ser un Daimon de la naturaleza. La sacralización de la naturaleza precede a la sacralización de los dioses. Señala Harrison que "la sacré, c'est le pére de Dieu" (Harrison, 1912: 63). No debemos identificar ingenuamente a Dios con lo sagrado, aquél es una manifestación específica, histórica, de éste. Zeus, cuyos orígenes radican en la naturaleza humana, sin embargo termina lanzando sus rayos contra la serpiente-alada o contra el toro salvaje (Harrison, 1912:448-449), contra el Daimon-Mana, y también dirigiendo sus diatribas contra el Titán rebelde, Prometeo, que -como señalábamos anteriormente- ha osado ayudar a los humanos. Progresivamente, Zeus emerge con forma humanizada, renunciando a sus orígenes naturales, en la medida en que "la atención del hombre se centra más y más en su propia humanidad, el culto ritual (Enyautos-Daimon) se convierte en algo peligroso y en una enfermedad que hay que evitar" (Harrison, 1912: 460).

d) Los dioses olímpicos rechazan las funciones del Enyautos-Daimon. En lugar de ser él mismo un sacramento dentro de la comida comunal que celebraba al 


\begin{abstract}
Daimon-Mana, el Dios olímpico pide el sacrificio de una víctima en el altar a él consagrado. El 'dios' del Enyautos-Daimon vive y trabaja para su gente, incluso hace más, muere por ellos. El Dios del nuevo orden de lo sagrado pretende ser inmortal. Examinando el sacramento y el sacrificio hemos visto que el Daimon anual en forma de toro muere para resucitar en medio de un rito regenerativo. La totalidad de su naturaleza es absorbida y expresada por el ciclo de reencarnaciones periódicas. Junto con la concepción de una inmortalidad muerta y estéril, crece la idea de que entre Dios y el hombre existe un hiatus insalvable. Los dioses son seres sagrados celosos de las potencialidades del Daimon-Mana. El Dios olímpico tiene personalidad individual, no es algo disperso en el mundo, como el Daimon-Mana.
\end{abstract}

En la fase preolímpica, el hombre no se había separado todavía de la naturaleza y no había desarrollado una conciencia de sí mismo separada de su grupo totémico, pero, en la medida en que el sistema grupal se desintegra, el individuo emerge, como ha visto Durkheim (1982) con gran precisión. El hombre siente, ciertamente e instintivamente, que un Dios es una cosa real -una cosa real porque es la proclamación real de una emoción colectiva inscrita en el ritual del Enyautos-Daimon, pero que, con el transcurso del tiempo, el propio hombre ha des-energetizado, intelectualizándolo hasta convertir a este Dios en concepto, en Eidolon, en ídolo. Esta es la secuencia de la metamorfosis que va de la emoción colectiva del Daimon al concepto, del animal totémico al Dios mistérico y de éste al Dios olímpico.

\title{
4. La metafísica del Logos como secularización del Dios olímpico
}

Hasta ahora hemos visto cómo, en un primer estadio evolutivo, la cosmovisión griega presenta un acentuado carácter mágico religioso expresado en torno al Daimon-Mana como potencialidad mágica y representado en torno al ritual del Enyautos-Daimon, presente en el Himno de los Kouretes. En este estadio, la 'divinidad' es una 'ley' de la naturaleza. En este contexto, lo natural es lo divino. En un período posterior hemos analizado la génesis social de los dioses en la forma de un politeísmo antropomórfico en el que la naturaleza y la divinidad se separan progresivamente: por un lado, la naturaleza se desacraliza paulatinamente, convirtiéndose la Physis en un principio metafísico; por otro lado, asistimos a una -también progresiva- sacralización de los dioses y las leyes de la sociedad, la familia y el Estado, que se identifican con la religión.

La vieja categoría matriarcal de Moira, que ya hemos mencionado anteriormente, y que originariamente significaba 'destino', significa también 'agro sorteado'. De acuerdo con esta acepción, a cada miembro de la comunidad le corresponde un lote de tierra sorteado según la praxis comunal en la que está inserto. Las Moiras (Greene, 1963: 9), como figuras míticas, representaban a los antepasados del clan matriarcal y su función era la de defender la integridad de estos derechos igualitarios (Thomson, 1972: 269-272). Lo mismo se puede decir de las Erinias, pero en el aspecto negativo, por cuanto que su función consistía en castigar la transgresión de la distribución hereditaria personificada en las Moiras. 
En el período de transición de la sociedad tribal-totémica a la sociedad de las ciudades-estado, estas imágenes quedaron relacionadas y subordinadas a Zeus, que representaba la monarquía y, más tarde, a Dike (Justicia). Ésta vigila el nuevo orden (la democracia) como las Erinias vigilaban el antiguo. De la misma forma que éstas reprimían la violación de Moira, Dike castiga la violación de Metrón (medida) y, así, de esta manera, la vieja categoría de Moira es reemplazada por la de Nomos (ley), la ley civil, que desliga a los individuos de los clanes y de su religación con la naturaleza, para conferirles una individualidad ciudadana. La vieja igualdad tribal-matriarcal proclamada ante la diosa Themis, se convierte en igualdad ante la ley, derecho común (Isonomía) frente al Estado. El destino natural originario -y no otra cosa es Moiraqueda reducido, bajo el imperio de la diosa Themis, a destino civil bajo la ley (Dike) y la medida (Metrón).

Dos factores importantes determinan el cambio de cosmovisión que nos lleva de la religión a la filosofía: la categoría de Logos y el nuevo principio de realidad, el Ser (Vernant, 1973: 347). Ambos configuran la revolución axial en el ámbito griego, es decir, la diferenciación entre el mundo trascendente de las formas-ideas y el mundo inmanente de la materia y los sentidos. Los significados fundamentales atribuibles a la categoría Logos, según Heráclito (1981: 352-355), son tres: discurso, razón de ser de algo y ratio. Así, podríamos definir el logos como el correcto análisis de la verdadera comprensión de la ley universal que gobierna la naturaleza, incluyendo a Dios y al hombre. No es una ley histórica o evolutiva, es más bien intemporal, como es eterno el mundo en el que opera, aunque sometido a cambio perpetuo. Tampoco es una ley natural que excluye lo divino, sino que más bien se identifica con ello por cuanto que es una abstracción inmaterial que representa todo lo que es general y absoluto en el universo como opuesto a lo particular y relativo.

Parménides significa el inicio de la metafísica racionalista del Ser. Según él, la verdad no puede ser aprehendida por los sentidos sino solo por la 'razón' (Logos), que es la 'razón pura'. Así lo afirma en la Vía de la Verdad (Parménides, 1981:477478). A su juicio queda un solo camino, el que es, el del Ser. Muchos signos llevan a esa vía: que el ser es in-engendrado e in-destructible, completo en su estructura, inmutable e in-finito. Nunca fue ni será porque es actualmente, es el Todo, Uno, continuo, definitivo. En él podemos encontrar los siguientes atributos (Parménides, 1981:479480). a) Es intemporal. No está sometido ni al nacimiento ni a la muerte, no tiene principio ni fin. b). Es indivisible puesto que es totalmente homogéneo, no puede ser en una parte más que en otra, por tanto, está lleno de Ser. c). Es inmóvil, reposa en sí mismo, persiste inmutablemente debido a que la poderosa Necesidad lo contiene dentro de las relaciones de un límite que lo constriñe por todas partes. Es inmóvil e inmutable porque es uno, y por ser uno es limitado. Ninguna otra cosa es ni será, excepto el ser, puesto que la Moira-Hado lo ha condenado a permanecer como totalidad inmóvil. Según Ortiz-Osés (1989:49), Parménides propondrá la famosa ad-ecuación entre el ser y el pensar. Como consecuencia de esto, el ser se redefine ahora con atributos de inmovilidad eidética, es decir, el Ser es Uno para el pensar y mucho (demasiado) para los sentidos. El Ser es puramente inteligible y, por tanto, solo captable por la Razón 
como verdadero. La sensibilidad solo aprehende la 'sombra' del Ser. Lo real auténtico es sólo el Ser; aquello que no es Ser no es, no tiene sentido, es apariencial.

Posteriormente, es Platón quien sistematiza y da cuerpo teórico a la propuesta de Parménides. Más en concreto, en su gran diálogo, La República (1981, libro VII: 551 y ss.), en lo que se conoce como 'analogía de la caverna', a través de un juego metafórico entre el mundo de la luz y el mundo de las sombras del interior de la caverna, Platón apunta que "las ideas inteligibles eternas que emanan de la Divinidad son prototipo, modelo y Logos de unas realidades cuya materialidad las distorsiona. Las ideas son los Números o relaciones ideales de lo real: lo matemático funda a priori el sentido sellado en nuestra proto-materia, materia eterna cual resto de la Magna Mater sometido al Dios-Logos" (Ortiz-Osés, 1989: 50). La existencia caduca encuentra su ser-sentido en la Pre-existencia y Post-existencia, es decir, en la reconducción de lo real hacia lo Ideal, de la existencia hacia la esencia, del fenómeno hacia su Noúmeno, de lo imperfecto por decadente hacia lo Perfecto apriórico y trascendente. Esta semilla metafísica dará lugar a todo el desarrollo de la cultura teórica que se extenderá por Occidente y, coextensivamente, por todo el mundo.

Parménides desacredita la evidencia de los sentidos como fuente de conocimiento y, en su lugar, sitúa al Logos como cumbre de una jerarquía de conocimiento. Esto significará que el énfasis puesto sobre las fuentes de conocimiento que fueron propiedad de la comunidad, con el mundo sensible como evidencia reconocida, se desplaza hacia fuentes de conocimiento que tienen como depositario último a una élite o minoría intelectual de filósofos como intérpretes cualificados. No obstante, estos grupos no forman en Grecia una 'comunidad de interpretación' homogénea sino que el diá-logos y la crítica (Momigliano, 1975: 9, nota 10) emerge entre grupos en competencia de élites institucionalizadas como son los sofistas, los místicos y los filósofos.

\section{Conclusiones}

El ritual y su potencialidad performativa, que en el mundo griego antiguo realiza su singladura inaugural en el Enyautos-Daimon relatado en el Himno de los Kouretes, no dejarán de existir en los momentos posteriores. Al inicio de este trabajo, Donald y Bellah nos mostraron cómo un nuevo estadio supone más bien una reconfiguración de viejas y nuevas posibilidades en lugar de una superación y desaparición de los estadios anteriores, así los juegos olímpicos y, posteriormente, la tragedia recogen la fuerza de la cultura mimética y la transforman. El Mythos es la trama, la cultura simbólica que recoge, re-presenta la historia de la vida del Enyautos-Daimon en invierno, en primavera, en verano o en otoño. Las formas áticas de drama son las formas de la historia de la vida actualizada en el Enyautos-Daimon, su contenido estará representado por la infinita variedad de la saga de héroes liberada del formato del ritual e individualizada, tal y como ha sido contado por Homero en sus obras. Éste marca un estadio en el que el pensamiento colectivo y el ritual mágico se transforman en teatro, tragedia, drama, una vez que el racionalismo y el pensamiento individualizado irrumpen en la sociedad. Las tramas del drama ático son liberadas de la rigidez ritual y son moldeadas por la voluntad del artista-actor, que actuará ante un auditorio, subsidiario de toda la communitas. 
A esto contribuyen, sin duda, las migraciones indoeuropeas que acrecientan el proceso de individualización divina y de progresiva des-daimonización. El Gran Kouros del Himno de los Kouretes aparecerá ya como el Dios Dionysos. Las formas rituales, por tanto, son preservadas en la tragedia griega (Murray, 1912: 341 y ss.). La performatividad teatral -a diferencia de la performatividad ritual- añade dos elementos novedosos: por una parte, tiene que atrapar la atención de Outsiders convirtiéndolos en una audiencia fascinada por la dramatización de la trama narrativa y, por otra parte, en contraste con los rituales, la performatividad teatral puede tener un final trágico: el mal, dicho en términos judeo-cristianos, puede prevalecer.

Hemos visto la formación de un Daimon-héroe a partir de la naturaleza sacralizada, después hemos visto a dicho Daimon-héroe cristalizado, individualizado en la figura de un Dios y, finalmente, el proceso de racionalización de las imágenes del mundo ha llevado a concentrar las propiedades del Dios en un principio abstracto metafísico, el Logos del Ser. Pero el nacimiento de la metafísica (filosofía) no significa la desaparición de la religión, tanto de la naturaleza daimónica (Enyautos-Daimon) como de las formas divinas antropomórficas representadas en el panteón olímpico politeísta. La filosofía traerá consigo otra forma de ritual, el político, la deliberación democrática (Alexander, 2011), que creará importantes fuerzas motrices para las grandes revoluciones y movimientos políticos modernos (Eisenstadt, 2007).

\section{Bibliografía}

Alexander, J. C. (2011): Performance and Power, Cambridge, Polity Press.

Anaximandro (1981): Los filósofos presocráticos, Madrid, Gredos, Vol. 1.

Bellah, R. N. (2011): Religion in the Human Evolution. From the Paleolithic to the Axial Age, Cambridge, The Belknap Press of the Harvard University.

Bellah, R. N. y H. Joas (eds.) (2012): The Axial Age and its Consequences, Cambridge, Harvard University Press.

Beriain J. (2015): "Genealogía afirmativa del hecho religioso en perspectiva religiosa", Revista Española de Investigaciones Sociológicas (REIS), 151, pp. 3-22.

Collins, R. (2009): Cadenas de rituales de interacción, Barcelona, Anthropos.

Cornford, F. M. (1912): "The origin of the Olympic Games", en J.E. Harrison, Themis. A study of the social origins of greek religion, Cambridge, Cambridge University Press, pp. 212-259.

Cornford, F. M. (1984): De la religión a la filosofía, Barcelona, Ariel.

Coromines, J. (2008): Breve diccionario etimológico de la lengua castellana, Madrid, Gredos.

Detienne M. y J.P. Vernant (eds.), (1979) : La cuisine du sacrifice en Pays Grec, Paris, Gallimard.

Donald, M. (1991): The Origins of the Modern Mind. Three Stages in the Evolution of Culture and Cognition, Cambridge, Harvard University Press.

Durkheim, E. (1982): Las formas elementales de la vida religiosa, Madrid, Akal.

Eisenstadt S. N. (1982): "The Axial Age. The Emergence of the Transcendental Visions and the Rise of Clerics", European Journal of Sociology, 23 (2), pp. 294-314. 
Eisenstadt S. N. (1985): "This Worldly Transcendentalism and the Structuring of the World. Weber's "Religion of China" and the Format of Chinese History and Civilization, Journal of Developing Societies, 1, pp. 168-186.

Eisenstadt, S. N. (2007): Las grandes revoluciones y las civilizaciones de la modernidad, Madrid, Centro de Estudios Políticos y Constitucionales.

Elkana, Y. (1986): "The Emergence of Second-Order Thinking in Classical Greece" en S. N. Eisenstadt (ed.), The Origins and Diversity of the Axial Civilizations, Albany, State University of New York, pp. 40-64.

Esquilo (1981): Las siete tragedias, México, Porrúa.

Giesen, B. (2006): "Performing the sacred: a Durkheimian perspective on the performative turn in the social sciences" en J. Alexander, B. Giesen y J. Mast (eds.) Social performance: Symbolic action, cultural pragmatics and ritual, New York, Cambridge University Press, pp. 325-367.

Girard, R. (1995): La violencia y lo sagrado, Barcelona, Anagrama.

Goffman, E. (1967): Interaction Ritual. Essays in Face-to-Face Behaviour, Pantheon Books, Nueva York.

Graves, R. (2002): Los mitos griegos (Vol. I), Madrid, Alianza.

Greene W. CH. (1944): Moira. Good, Fate and Evil in Greek Thought, Nueva York, Harper and Row.

Harrison, J. E. (1912): Themis. A Study of the Social Origins of Greek Religion, Cambridge, Cambridge University Press.

Heráclito (1981): Los filósofos presocráticos, Madrid, Gredos, Vol. 1.

Hesiodo (1981): Teogonía y otras obras, México, Porrua.

Hénaff, M. (2010): The Price of Truth. Gift, Money and Philosophy, Stanford, Stanford University Press.

Hubert, H., Mauss, M. (1964): Sacrifice: Its Nature and Functions, Chicago, The University of Chicago Press.

Joas, H. (2014): The sacredness of the person, Georgetown, Georgetown University Press.

Mauss, M. (1978): Sociología y antropología, Madrid, Tecnos.

Mead G. H. (1982): Espiritu, persona y sociedad, Barcelona, Paidos.

Meier, Ch. (1986): "The Emergence of an Autonomous Intelligence among the Greeks" en S.N. Eisenstadt (ed.), The Origins and Diversity of the Axial Civilizations, Albany, State University of New York, pp. 65-91.

Momigliano, A. (1975): Alien Wisdom. The Limits of Hellenization, Cambridge, Cambridge University Press.

Murray, G. (1912): "Excursus on the ritual forms preserved in Greek Tragedy" en J.E. Harrison, Themis. A study of the social origins of Greek religion, Cambridge, Cambridge University Press, pp. 341-363.

Ortiz-osés, A. (1989): Metafisica del sentido, Bilbao, Ediciones Deusto.

Otto, R. (2012): Lo santo, Madrid, Alianza.

Parménides, (1981): Los filósofos presocráticos, Madrid, Gredos, Vol. 1.

Píndaro (1967): Olímpicas, Madrid, Aguilar.

Platón (1981): "La República” en Diálogos, Ciudad de México, Porrúa. 
RAE (2005), Diccionario de la lengua española (Vol. II), Madrid, Espasa.

Robertson-Smith, W. (1889): Lectures on the Religion of the Semites. First Series: The Fundamental Institutions, Nueva York, Appleton and Company.

Schmalenbach, H. (1977): "Communion. A Sociological Category" en Lüschen G., y G. P. Stone (Eds.), On Society and Experience, Chicago, The University of Chicago Press, pp. 64-125.

Schwartz, B. (1975): "The Age of Transcendence" en Wisdom, Revelation and Doubt, Daedalus, Spring 2, pp. 3-4.

Thomson, G. (1972): Los Primeros filósofos, Buenos Aires, Siglo Veinte.

Turner, V (1988): El proceso ritual, Madrid, Taurus.

Vernant, J. P. (1973): Mito y pensamiento en la Grecia Antigua, Barcelona, Ariel.

Weber, M. (1975): El político y el cientifico, Madrid, Alianza.

Wittrock, B. (2012): "The Axial Age in Global History. Cultural Crystallization and Societal Transformation" en R.N. Bellah y H. Joas (eds.), The Axial Age and its Consequences, Cambridge, The Belknap of the Harvard University Press, pp.102126. 